\title{
Prediksi Erosi Pada Lahan Tanaman Kopi Arabika (Coffea arabica L.) di Kabupaten Gayo Lues Menggunakan Metode USLE
} (Prediction of Soil Erosion on Arabica Coffee plantation (Coffea arabica L) in Gayo Lues Regency With USLE)

\author{
Riska Ullyana $^{1}$, Manfarizah ${ }^{1}$, Syakur $^{1 *}$ \\ ${ }^{1}$ Program Studi Ilmu Tanah, Fakultas Pertanian, Universitas Syiah Kuala \\ *Corresponding author: syakur@unsyiah.ac.id
}

\begin{abstract}
Abstrak. Erosi adalah peristiwa terangkutnya tanah dari suatu tempat ke tempat lain oleh media alami. Sampel tanah diambil dari 10 satuan peta lahan (SPL) yang terdapat pada kebun kopi di Kabupaten Gayo Lues. Perhitungan Erosi menggunakan metode USLE yang faktor penilaiannya adalah faktor erodibilitas, faktor curah hujan, faktor lereng, faktor vegetasi dan faktor konservasi. Terdapat 3 kategori kelas Tingkat Bahaya Erosi (TBE) potensial yaitu kelas sedang terdapat pada SPL 1. Kelas berat terdapat pada SPL 6. Kelas sangat berat terdapat pada SPL 2, SPL 3, SPL 4, SPL 5, SPL 7, SPL 8, SPL 9, dan SPL 10. Terdapat 4 kategori kelas Tingkat Bahaya Erosi (TBE) aktual yaitu kelas sangat ringan terdapat pada SPL 1, SPL 6, SPL 9. Kelas ringan terdapat pada SPL 2, SPL 5, SPL 7. Kelas berat terdapat pada SPL 3 dan SPL 8. Kelas sangat berat terdapat pada SPL 4.
\end{abstract}

Kata kunci : Prediksi Erosi, Kebun Kopi, Metode USLE

\begin{abstract}
Erosion is the event of the transport of soil from one place to another by natural media. Soil samples were taken from 10 land map units (SPL) found in coffee plantations in Gayo Lues Regency. The calculation of erosion uses the USLE method which the assessment factors are erodibility factors, rainfall factors, slope factors, vegetation factors and conservation factors. There are 3 categories of potential Erosion Danger Level (TBE) classes, namely moderate class at SPL 1 . Heavy class is found at SPL 6. Very heavy class is found at SPL 2, SPL 3, SPL 4, SPL 5, SPL 7, SPL 8, SPL 9, and SPL 10. There are 4 categories for the actual Erosion Danger Level (TBE) class, namely the very light class at SPL 1, SPL 6, SPL 9. Light class is at SPL 2, SPL 5, SPL 7. Heavy class is found at SPL 3 and SPL 8. Very heavy class is found at SPL 4.
\end{abstract}

Keywords: Erosion Prediction, Coffee Plantation, USLE Method

\section{PENDAHULUAN}

Tanah sebagai sumber daya alam mengalami berbagai macam tekanan seiring terjadinya peningkatan jumlah manusia. Hal tersebut telah menyebabkan degradasi tanah yang mengakibatkan penurunan daya tanah untuk berproduksi. Menurut Arsyad (2012), degradasi tanah disebabkan oleh hilangnya unsur hara dan bahan organik dari daerah perakaran, erosi dan beberapa hal lainnya.

Kopi juga merupakan tanaman tahunan yang diusahakan di Indonesia terutama di dataran tinggi Gayo. Menurut sejarahnya nama kopi diambil dari nama sebuah kota di negara Abessina (Etiophia) yaitu kota Caffa yang dikenal sebagai pusat perkopian pertama di dunia. Menurut data Badan Pusat Statistik (BPS) tahun 2018 hampir seluruh kecamatan di Kabupaten Gayo Lues terdapat perkebunan kopi, namun terdapat tiga kecamatan yang memiliki perkebunan kopi terluas di kabupaten ini diantaranya: Kecamatan Blangkejeren seluas 792 ha, Kecamatan Dabun Gelang seluas 811 ha, dan Kecamatan Pantan Cuaca seluas 1.115 ha.

Letak geografis Kabupaten Gayo Lues berada pada 96 $43^{\prime} 24^{\prime \prime}-97^{\circ} 55^{\prime} 24 " \mathrm{BT}$ dan $3^{\circ}$ $40^{\prime} 26^{\prime \prime}-4^{\circ} 16^{\prime} 55^{\prime \prime}$ LU. Wilayah Kabupaten Gayo Lues terletak di ketinggian 100-3000 meter di atas permukaan laut (mdpl). Pada tahun 2017, kopi merupakan komoditas terbanyak ketiga hasil panennya di Kabupaten Gayo Lues yaitu sebanyak 2.090 ton dan jenis kopi yang ditanami adalah kopi arabika yang produktivitasnya maksimal apabila ditanami pada ketinggian diatas 1000 mdpl (BPS, 2018).

Kabupaten Gayo Lues 43,93\% wilayahnya berada di kemiringan di atas $40 \%$ yang berupa pegunungan. Dalam penelitiannya Izzati (2019) menyebutkan bahwa kemiringan lereng akan 
mempengaruhi tingkat bahaya erosi yang dihasilkan, semakin besar persen kemiringan lereng maka akan semakin besar tingkat erosi yang dihasilkan. Beberapa perkebunan kopi di Gayo Lues seluas 10.968,35 $\mathrm{m}^{\wedge} 2$ tanaman kopi ditanam pada lereng $26 \%$ hingga lebih dari $40 \%$ dan tanpa mengikuti kaidah tindakan konservasi tanah dan kesuburan tanah yang rendah. Selain masalah kemiringan lereng, Kabupaten Gayo Lues juga memiliki rata-rata curah hujan 1.997,93 $\mathrm{mm} /$ tahun dan besarnya laju erosi juga dapat dipengaruhi oleh intensitas curah hujan yang terjadi, dengan meningkatnya intensitas curah hujan yang terjadi, maka laju erosinya juga meningkat.

Penjagaan tanah diperlukan agar tanah tetap subur dan mutunya tetap terjaga. Sebagaimana telah dibahas sebelumnya, penurunan mutu tanah salah satunya disebabkan oleh erosi. Oleh karena itu prediksi erosi pada lahan kebun kopi sangat diperlukan untuk memberikan informasi kepada petani tingkat erosi yang terjadi pada kebun kopi dan dapat memberikan solusi untuk mengurangi erosi pada kebun kopi milik mereka.

\section{METODE PENELITIAN}

Kabupaten Gayo Lues adalah tempat dilaksanakannya penelitian. Lokasi penelitian adalah perkebunan kopi yang terdapat di Kabupaten Gayo Lues. Pengambilan sampel tanah dilakukan dengan metode survei tanah di lapangan berdasarkan satuan peta lahan (SPL). Selanjutnya analisis dilaksanakan di Laboratorium Fisika Tanah dan juga di Laboratorium Kimia Tanah. Penelitian ini dilaksanakan pada tanggal 10 Oktober 2019 sampai dengan 30 Januari 2020.

\section{Alat dan Bahan}

Alat yang digunakan untuk penelitian ini adalah GPS, cangkul, pisau tanah, bor tanah, ring sample, meteran, kertas label, dan alat tulis. Adapun bahan yang digunakan untuk penelitian ini adalah data curah hujan Kabupaten Gayo Lues tahun selama 10 tahun, peta administrasi Kabupaten Gayo Lues skala 1: 100.000, peta penggunaan lahan Kabupaten Gayo Lues skala 1: 100.000, peta jenis tanah Kabupaten Gayo Lues skala 1: 100.000, peta kelerengan Kabupaten Gayo Lues, dan peta persebaran perkebunan kopi Kabupaten Gayo Lues

\section{Metode Penelitian}

Penlitian ini menggunakan metode survei deskriptif, yang didasarkan pada hasil pengamatan di lapangan dengan menggunakan SPL (Satuan Peta Lahan), dan analisis tanah di laboratorium.

\section{Penentuan Besar Laju Erosi}

Penentuan besar laju erosi prediksi erosi dilakukan dengan metode USLE karena metode ini sangat sederhana dan seluruh variabelnya dapat ditemukan kawasan kajian. Berikut adalah persamaannya:

Keterangan:

$$
A=R \cdot K \cdot L . S . C . P
$$

A: Tanah yang tererosi dalam ton $\mathrm{ha}^{-1} \mathrm{th}^{-1}$;

R: Curah hujan

K: Erodibilitas tanah

L: Panjang lereng

S: Kecuraman lereng

$\mathrm{C}$ : Vegetasi penutup tanah dan pengelolaan tanaman

$P$ : Tindakan konservasi tanah

Penentuan TBE (Tingkat Bahaya Erosi) menggunakan Tabel 1. Dalam penentuannya hanya menggunakan informasi solum tanah dan nilai prediksi erosi menggunakan metode USLE. 
Tabel 1. Kelas Tingkat Bahaya Erosi

\begin{tabular}{cccccc}
\hline & \multicolumn{5}{c}{ Kelas Erosi } \\
\cline { 2 - 6 } Solum Tanah (cm) & I & II & III & IV & V \\
\cline { 2 - 6 } & \multicolumn{5}{c}{$\begin{array}{c}\text { Erosi } \\
\left(\text { ton ha }^{-1} \text { th }^{-1}\right)\end{array}$} \\
\cline { 2 - 6 } & $<15$ & $15-60$ & $60-180$ & $180-480$ & $>480$ \\
\hline Dalam & SR & R & S & B & SB \\
$>90$ & 0 & I & II & III & IV \\
Sedang & R & S & B & SB & SB \\
$90-60$ & I & II & III & IV & IV \\
Dangkal & S & B & SB & SB & SB \\
$60-30$ & II & III & IV & IV & IV \\
Sangat Dangkal & B & SB & SB & SB & SB \\
$<30$ & III & IV & IV & IV & IV \\
\hline
\end{tabular}

Sumber : Departemen Kehutanan, Direktorat Jenderal Reboisasi dan Rehabilitasi Lahan (1998)

Keterangan :

$\begin{array}{ll}\text { 0-SR } & =\text { Sangat Ringan } \\ \text { I-R } & =\text { Ringan } \\ \text { II-S } & =\text { Sedang } \\ \text { III-B } & =\text { Berat } \\ \text { IV-SB } & =\text { Sangat Berat }\end{array}$

\section{HASIL DAN PEMBAHASAN}

\section{Satuan Peta Lahan}

Penentuan Satuan Peta Lahan (SPL) dilakukan dengan menumpang susunkan (overlay) peta penggunaan lahan, peta jenis tanah dan peta lereng dengan menggunakan menu union pada aplikasi ArcMap dan didapatkan 10 satuan peta lahan dengan karakteristik lahan berbeda. Adapun data deskripsi SPL dapat dilihat pada Tabel 2.

Tabel 2. Deskripsi SPL Lokasi Pengambilan Sampel

\begin{tabular}{rrrccrr}
\hline \multirow{2}{*}{ No } & SPL & $\begin{array}{c}\text { Penggunaan } \\
\text { Lahan }\end{array}$ & Jenis Tanah & Kemiringan Lereng & Ha & Persentase \\
\cline { 3 - 7 } 1 & SPL 1 & Kopi Arabika & Ultisol & $<8 \%$ & 147,57 & 12,28 \\
2 & SPL 2 & Kopi Arabika & Ultisol & $8 \%-15 \%$ & 347,50 & 28,92 \\
3 & SPL 3 & Kopi Arabika & Ultisol & $16 \%-25 \%$ & 522,02 & 43,44 \\
4 & SPL 4 & Kopi Arabika & Ultisol & $26 \%-40 \%$ & 19,51 & 1,62 \\
5 & SPL 5 & Kopi Arabika & Ultisol & $>40 \%$ & 13,61 & 1,13 \\
6 & SPL 6 & Kopi Arabika & Entisol & $<8 \%$ & 26,28 & 2,19 \\
7 & SPL 7 & Kopi Arabika & Entisol & $<8 \%-15 \%$ & 64,82 & 5,39 \\
8 & SPL 8 & Kopi Arabika & Entisol & $16 \%-25 \%$ & 33,32 & 2,77 \\
9 & SPL 9 & Kopi Arabika & Inceptisol & $<8 \%$ & 1,56 & 0,13 \\
10 & SPL 10 & Kopi Arabika & Inceptisol & $8 \%-15 \%$ & 25,40 & 2,11 \\
\hline & & TOTAL & & & $\mathbf{1 2 0 1 , 5 8}$ & 100,00 \\
\hline
\end{tabular}

Sumber: Hasil analisis peta (2019) 


\section{Penilaian Faktor- Faktor Erosi}

\section{a. Faktor Erosivitas Hujan (R)}

Nilai erosivitas hujan tahunan pada kawasan kajian yaitu $1240,33 \mathrm{~cm}^{\text {th^}} \wedge(-1)$. Hardjowigeno (1995) menyebutkan curah hujan adalah sifat hujan yang sangat besar pengaruhnya terhadap erosi karena kekuatannya dalam menghancurkan tanah sangat besar daripada kekuatan penganggut aliran permukaan.

\section{b. Faktor Erodibilitas Tanah (K)}

Variabel tanah yang dianalisis di laboratorium adalah tekstur tanah menggunakan metode pipet 4 fraksi, kadar C-organik dengan metode Walkey and Black, dan permeabilitas dengan metode penggenangan. Setelah didapat nilai- nilai dari semua sifat tanah yang mempengaruhi erodibilitas, kemudian dihitung menggunakan persamaan 3 . Nilai hasil perhitungan faktor erodibilitas dapat dilihat pada Tabel 3.

Tabel 3. Nilai Erodibilitas (K) pada Setiap SPL

\begin{tabular}{|c|c|c|c|}
\hline No & SPL & $\left.2,71 \times 10^{-4}(12-\mathrm{BOT}) \mathrm{M}^{1,14}+3,25(\mathrm{~S}-2)+2,5(\mathrm{P}-3)\right\} / 100$ & $\begin{array}{l}\text { Nilai Kepekaan } \\
\text { Erosi }\end{array}$ \\
\hline 1 & SPL 1 & 0,31 & Sedang \\
\hline 2 & SPL 2 & 0,67 & Sangat Tinggi \\
\hline 3 & SPL 3 & 0,38 & Agak Tinggi \\
\hline 4 & SPL 4 & 0,56 & Sangat Tinggi \\
\hline 5 & SPL 5 & 0,24 & Sedang \\
\hline 6 & SPL 6 & 0,85 & Sangat Tinggi \\
\hline 7 & SPL 7 & 0,78 & Sangat Tinggi \\
\hline 8 & SPL 8 & 0,34 & Sedang \\
\hline 9 & SPL 9 & 0,52 & Tinggi \\
\hline 10 & SPL 10 & 0,53 & Tinggi \\
\hline
\end{tabular}

Poesen (1983) menyatakan bahwa erodibilitas atau kepekaan erosi ditentukan oleh faktor- faktor erosi seperti erosivitas, , vegetasi, topografi, aktiviyas manusia, fauna dan tidak hanya oleh sifat-sifat tanah.

\section{c. Faktor Panjang Lereng dan Kemiringan Lereng (LS)}

Anthony (2001) menyebutkan, kondisi lahan yang landai lebih stabil, peningkatan erosi dengan cepat apabila keiringannya bertambah menjadi 2\%-5\%. Erosi akan meningkat menjadi delapan kali lebih tinggi pada kemiringan lereng 10\%, dan meningkat lagipada kemiringan lereng $15 \%$. Nilai hasil perhitungan faktor LS dapat dilihat pada Tabel 4.

Tabel 4. Nilai Faktor Panjang Lereng dan Kemiringan Lereng (LS)

\begin{tabular}{cccc}
\hline No & SPL & Kemiringan Lereng & Nilai LS \\
\hline $\mathbf{1}$ & SPL 1 & $<8 \%$ & 0,40 \\
$\mathbf{2}$ & SPL 2 & $<8 \%-15 \%$ & 1,40 \\
$\mathbf{3}$ & SPL 3 & $16 \%-25 \%$ & 3,10 \\
$\mathbf{4}$ & SPL 4 & $26 \%-40 \%$ & 6,40 \\
$\mathbf{5}$ & SPL 5 & $>40 \%$ & 9,50 \\
$\mathbf{6}$ & SPL 6 & $<8 \%$ & 0,40 \\
$\mathbf{7}$ & SPL 7 & $<8 \%-15 \%$ & 1,40 \\
$\mathbf{8}$ & SPL 8 & $16 \%-25 \%$ & 3,10 \\
$\mathbf{9}$ & SPL 9 & $<8 \%$ & 0,40 \\
$\mathbf{1 0}$ & SPL 10 & $8 \%-15 \%$ & 1,40 \\
\hline
\end{tabular}




\section{d. Faktor Pengelolaan Tanaman dan Konservasi Tanah (CP)}

Setelah diketahui nilai $\mathrm{C}$ dan nilai $\mathrm{P}$ kemudian dilakukan perkalian terhadap nilai keduanya. Nilai CP yang lebih jelas dapat dilihat pada Tabel 5.

Tabel 5. Nilai Faktor Pengelolaan Tanaman (C)

\begin{tabular}{|c|c|c|c|c|c|}
\hline No & SPL & Vegetasi & Pengelolaan Tanaman & Teknik Konservasi & Nilai $\mathrm{CP}$ \\
\hline 1 & SPL 1 & Kopi, Lamtoro & $\begin{array}{l}\text { Kebun Campuran dengan } \\
\text { Kerapatan Sedang }\end{array}$ & $\begin{array}{l}\text { Penutup Tanah } \\
\text { Rapat }\end{array}$ & 0,02 \\
\hline 2 & SPL 2 & Kopi, Lamtoro & $\begin{array}{l}\text { Kebun Campuran dengan } \\
\text { Kerapatan Sedang }\end{array}$ & $\begin{array}{l}\text { Penutup Tanah } \\
\text { Rapat }\end{array}$ & 0,02 \\
\hline 3 & SPL 3 & Kopi, kakao & $\begin{array}{l}\text { Kebun Campuran dengan } \\
\text { Kerapatan Rendah }\end{array}$ & $\begin{array}{l}\text { Penutup Tanah } \\
\text { sedang }\end{array}$ & 0,25 \\
\hline 4 & SPL 4 & Kopi, Cabe & $\begin{array}{l}\text { Kebun Campuran dengan } \\
\text { Kerapatan Rendah }\end{array}$ & $\begin{array}{l}\text { Penutup Tanah } \\
\text { Sedang }\end{array}$ & 0,25 \\
\hline 5 & SPL 5 & Kopi, Lamtoro & $\begin{array}{l}\text { Kebun Campuran dengan } \\
\text { Kerapatan Sedang }\end{array}$ & $\begin{array}{c}\text { Penutup Tanah } \\
\text { Rapat }\end{array}$ & 0,02 \\
\hline 6 & SPL 6 & Kopi, Lamtoro & $\begin{array}{l}\text { Kebun Campuran dengan } \\
\text { Kerapatan Sedang }\end{array}$ & $\begin{array}{c}\text { Penutup Tanah } \\
\text { Rapat }\end{array}$ & 0,02 \\
\hline 7 & SPL7 & Kopi, Lamtoro & $\begin{array}{l}\text { Kebun Campuran dengan } \\
\text { Kerapatan Sedang }\end{array}$ & $\begin{array}{c}\text { Penutup Tanah } \\
\text { Rapat }\end{array}$ & 0,02 \\
\hline 8 & SPL 8 & Kopi, kakao & $\begin{array}{l}\text { Kebun Campuran dengan } \\
\text { Kerapatan Rendah }\end{array}$ & $\begin{array}{l}\text { Penutup Tanah } \\
\text { Sedang }\end{array}$ & 0,25 \\
\hline 9 & SPL 9 & Kopi, Lamtoro & $\begin{array}{l}\text { Kebun Campuran dengan } \\
\text { kerapatan Sedang }\end{array}$ & $\begin{array}{l}\text { Penutup Tanah } \\
\text { Rapat }\end{array}$ & 0,02 \\
\hline 10 & SPL 10 & Kopi, Lamtoro & $\begin{array}{c}\text { Kebun Campuran dengan } \\
\text { Kerapatan Sedang }\end{array}$ & $\begin{array}{c}\text { Penutup Tanah } \\
\text { Rapat }\end{array}$ & 0,02 \\
\hline
\end{tabular}

\section{e. Prediksi Erosi}

Tabel 6. Nilai Prediksi Erosi dan Tingkat Bahaya Erosi (TBE)

\begin{tabular}{ccccccccc}
\hline No & SPL & $\mathbf{R}$ & $\mathbf{K}$ & $\mathbf{L S}$ & $\mathbf{C P}$ & $\begin{array}{c}\mathbf{A}=\mathbf{R}^{*} \mathbf{K}^{* \mathbf{L} \mathbf{*}} \mathbf{*} \mathbf{C P} \\
\left(\mathbf{t o n} \mathbf{h a}^{-\mathbf{1}} \mathbf{t h}^{\mathbf{1}}\right)\end{array}$ & $\begin{array}{c}\text { Solum } \\
\mathbf{T a n a h} \\
(\mathbf{c m})\end{array}$ & $\begin{array}{c}\text { Tingkat } \\
\text { Bahaya Erosi } \\
\text { (TBE) }\end{array}$ \\
\hline $\mathbf{1}$ & SPL 1 & 1240,33 & 0,31 & 0,40 & 0,02 & 3,08 & 93 & Sangat Ringan \\
$\mathbf{2}$ & SPL 2 & 1240,33 & 0,67 & 1,40 & 0,02 & 23,27 & 93 & Ringan \\
$\mathbf{3}$ & SPL 3 & 1240,33 & 0,38 & 3,10 & 0,25 & 365,28 & 96 & Berat \\
$\mathbf{4}$ & SPL 4 & 1240,33 & 0,56 & 6,40 & 0,25 & 1111,34 & $>100$ & Sangat Berat \\
$\mathbf{5}$ & SPL 5 & 1240,33 & 0,24 & 9,50 & 0,02 & 56,56 & 94 & Ringan \\
$\mathbf{6}$ & SPL 6 & 1240,33 & 0,85 & 0,40 & 0,02 & 8,43 & $>100$ & Sangat Ringan \\
$\mathbf{7}$ & SPL 7 & 1240,33 & 0,78 & 1,40 & 0,02 & 27,09 & 96 & Ringan \\
$\mathbf{8}$ & SPL 8 & 1240,33 & 0,34 & 3,10 & 0,25 & 326,83 & 100 & Berat \\
$\mathbf{9}$ & SPL 9 & 1240,33 & 0,52 & 0,40 & 0,02 & 5,16 & 83 & Sangat Ringan \\
$\mathbf{1 0}$ & SPL 10 & 1240,33 & 0,53 & 1,40 & 0,02 & 18,41 & 97 & Ringan \\
\hline
\end{tabular}

Erosi terkecil terdapat pada SPL 1 yaitu sebesar 3,08 ton ha ${ }^{-1}$ th $^{-1}$ dengan kelas TBE sangat ringan dan jenis tanah pada SPL ini adalah Ultisol dengan lereng $<8 \%$. Erosi terbesar terjadi pada SPL 4 yaitu sebesar 1111,34 ton $\mathrm{ha}^{-1} \mathrm{th}^{-1}$ yang memiliki jenis tanah Ultisol dengan lereng 26\%-40\% dengan kelas TBE sangat berat. Bila membandingkan penyebab perbedaan besaran erosi pada kedua SPL ini disebabkan oleh faktor kemiringan lereng, faktor vegetasi dan tindakan konservasi (CP), SPL 4 memiliki kemiringan lereng yang curam dan pengelolaan tanamannya dikategorikan dalam kebun campuran dengan kerapatan rendah dan teknik konservasinya dikategorikan dalam penutup tanah sedang sedangkan SPL 1 memiliki 
kemiringan lereng yang landai dan pengelolaan tanamannya dikategorikan dalam kebun campuran dengan kerapatan sedang dengan teknik konservasinya dikategorikan dalam penutup tanah rapat.

Menurut Arsyad (2012), kemiringan lereng sangat mempengaruhi terjadi erosi, semakin curam suatu lereng maka semakin cepat pula aliran permukaan mengangkut tanah.

\section{f. Arahan Konservasi Lahan}

Tabel 7. Arahan Konservasi Lahan

\begin{tabular}{|c|c|c|c|c|c|c|}
\hline No & SPL & $\begin{array}{c}\text { Jenis } \\
\text { Tanah }\end{array}$ & Lereng & $\begin{array}{c}\text { Erosi } \\
\text { Aktual }\end{array}$ & TBE Aktual & Arahan Konservasi \\
\hline 1 & SPL 1 & Ultisol & $<8 \%$ & 3,08 & Sangat Ringan & $\begin{array}{c}\text { Cover crop, penyiangan } \\
\text { parsial }\end{array}$ \\
\hline 2 & SPL 2 & Ultisol & $<8 \%-15 \%$ & 23,27 & Ringan & $\begin{array}{c}\text { Cover crop, penyiangan } \\
\text { parsial }\end{array}$ \\
\hline 3 & SPL 3 & Ultisol & $16 \%-25 \%$ & 365,28 & Berat & $\begin{array}{c}\text { Cover crop, penyiangan } \\
\text { parsial }\end{array}$ \\
\hline 4 & SPL 4 & Ultisol & $26 \%-40 \%$ & 1111,34 & Sangat Berat & Agroforestri \\
\hline 5 & SPL 5 & Ultisol & $>40 \%$ & 56,56 & Ringan & $\begin{array}{c}\text { Cover crop, penyiangan } \\
\text { parsial }\end{array}$ \\
\hline 6 & SPL 6 & Entisol & $<8 \%$ & 8,43 & Sangat Ringan & $\begin{array}{c}\text { Cover crop, penyiangan } \\
\text { parsial }\end{array}$ \\
\hline 7 & SPL 7 & Entisol & $<8 \%-15 \%$ & 27,09 & Ringan & $\begin{array}{c}\text { Cover crop, penyiangan } \\
\text { parsial }\end{array}$ \\
\hline 8 & SPL 8 & Entisol & $16 \%-25 \%$ & 326,83 & Berat & $\begin{array}{c}\text { Cover crop, penyiangan } \\
\text { parsial }\end{array}$ \\
\hline 9 & SPL 9 & Inceptisol & $<8 \%$ & 5,16 & Sangat Ringan & $\begin{array}{c}\text { Cover crop, penyiangan } \\
\text { parsial }\end{array}$ \\
\hline 10 & SPL 10 & Inceptisol & $8 \%-15 \%$ & 18,41 & Ringan & $\begin{array}{c}\text { Cover crop, penyiangan } \\
\text { parsial }\end{array}$ \\
\hline
\end{tabular}

SPL yang memiliki kelas TBE sangat ringan yaitu SPL 1, SPL 6, dan SPL 9. Sedangkan SPL yang memiliki kelas TBE ringan yaitu SPL 2, SPL 5, SPL 7, dan SPL 10. Arahan konservasi yang disarankan untuk SPL tersebut adalah cover crop dan penyiangan parsial. Penggunaan cover crop atau tanaman penutup tanah seperti gulma adalah salah satu tindakan konservasi. Cover crop disarankan karena fungsinya yang dapat mencegah air hujan jatuh langsung mengenai tanah begitu juga halnya dengan penyiangan parsial.

SPL yang kelas TBE berat adalah SPL 3 dan SPL 8. Arahan konservasi yang disarankan untuk SPL tersebut adalah cover crop dan penyiangan parsial. Hafif B et al. (2014) mengatakan bahwa dengan melakukan penyiangan secara parsial yaitu penyiangan yang hanya dilakukan pada strip tanaman yang lebar tajuknya $120 \mathrm{~cm}$ sehingga mengurangi limpasan permukaan dan gulma dipotong pendek dapat menjaga butir-butir tanah dari kerusakan akibat kekuatan air hujan yang jatuh, hal tersebut dapat menekan laju erosi. Choiron (2010) mengatakan bahwa saat tumbuh dan berkembangnya tajuk tanaman kopi terbentuklah lapisan serasah pada tanah. Selain itu juga karena pada saat hujan, air hujan tidak langsung jatuh ke tanah, adanya pohon pelindung tanaman kopi dan tajuk tanaman kopi yang lebar dapat mengurangi kekuatan air hujan sebelum jatuh ketanah.

SPL yang memiliki TBE sangat berat adalah SPL 4, pada SPL 4 disarankan penggunaan sistem agroforestri karena masalah pada SPL ini adalah berada pada lereng $26 \%-40 \%$ dan faktor pengelolaan tanamannya dikategorikan dalam kebun campuran dengan kerapatan rendah dengan faktor teknik konservasinya dikategorikan dalam penutup tanah sedang karena baru 
ditanami kopi namun belum ada naungan. Menurut Agus et al (2002) penggunaan sistem agroforestri dengan penanaman pohon pelindung sebagai vegetasi penutup tanah (C) merupakan sistem konservasi yang sangat baik

\section{KESIMPULAN DAN SARAN}

Terdapat 4 kategori kelas Tingkat Bahaya Erosi (TBE) aktual yaitu kelas sangat ringan terdapat pada SPL 1, SPL 6, SPL dan SPL 9. Kelas ringan terdapat pada SPL 2, SPL 6, dan SPL 7. Kelas berat terdapat SPL 3 dan SPL 8. Kelas sangat berat terdapat pada SPL 4. Arahan konservasi yang disarankan untuk SPL dengan kelas TBE sangat ringan, ringan, dan berat adalah cover crop dan penyiangan parsial sedangkan untuk SPL dengan Kelas TBE sangat berat adalah agroforestri

\section{DAFTAR PUSTAKA}

Agus, F., A.N. Gintings, dan M. van Noordwijk. 2002. Pilihan teknologi agroforestri atau konservasi tanah untuk areal pertanian berbasis kopi di Sumberjaya, Lampung Barat. World Agroforestry Centre, Bogor

Anthony, F.J. 2001. Soil Erosion and Conservation. Seafriends Marine Conservation and Education Centre. 7 Goat Island Rd. Leigh R.D.5. New Zealand.

Arsyad, S. 2012. Konservasi tanah dan air. Edisi kedua Cetakan kedua. Bogor (ID): Penerbit IPB Press. Bogor

BPS Gayo Lues, 2018. Gayo Lues Dalam Angka 2018. https://gayolueskab.bps.go.id diakses pada 10 April 2019.

Choiron, M. 2010. Penerapan GMP pada penanganan pascapanen kopi rakyat untuk menurunkan okratoksin produk kopi (Studi Kasus di Sidomulyo, Jember). Agrointek 4 (2): 114-120.

Haerdjowigeno, S. 1995. Ilmu Tanah. Akademika Presindo. Jakarta.

Hafif B, B. Prastowo, dan P. Risdiono. 2014. Pengembangan Perkebunan Kopi Berbasis Inovasi Di Lahan Kering Masam. Balai Pengkajian Teknologi Pertanian Lampung. Bandar Lampung..

Izzati R, 2019. Kajian kesesuaian lahan dan pengembangan kopi arabika di Kabupaten Gayo Lues. Fakultas Pertanian. Universitas Syiah Kuala. Banda Aceh.

Poesen, J. 1981. Rainwash experiment on the erodibility of loose sediments earth surf. Proch. landform 6: 285-307.

Wischmeier W.H, Smith DD. 1978. Predicting rainfall erosion losses a guide to conservation planning. USDA Agric. Handb (537): 58. 